\title{
Functional morphology and modifications on spine growth in the productid brachiopod Heteralosia slocomi
}

\author{
Alberto Pérez-Huerta \\ Acta Palaeontologica Polonica 58 (2), 2013: 383-390 doi: http://dx.doi.org/10.4202/app.2010.0096
}

Spines are one of the most characteristic ornamenting features of many fossil brachiopod taxa. Despite several studies of spines in different species, there is still insufficient information about the development, functionalmorphology, and modifications of brachiopod spines. In particular, ontogenetic data are very rare and the understanding of the relationship between functional morphology and paleoecology is elusive. The present study analyzes the functional morphology and modifications on spines of the Pennsylvanian brachiopod species Heteralosia slocomi throughout ontogeny. Spines are tubular hollow and only displayed on the surface of the ventral valves, where they develop from a specific point at the margins of the growth lamellae and directed towards the antero-lateral margins.Modifications of up to $180 \square$ from this original direction of growth are observed in response to ecological pressure and biotic interactions. The function of these spines is primarily for attachment by clasping and cementation, but the possibility of spines acting as sensory mechanisms is not excluded.

Key words: Brachiopoda, Productida, tubular hollow spine, silicification, ontogeny, paleoecology, Pennsylvanian, USA.

Alberto Pérez-Huerta [aphuerta@ as.ua.edu], Department of Geological Sciences, 2018 Bevill Building, The University of Alabama, Tuscaloosa AL 35487, USA.

This is an open-access article distributed under the terms of the Creative Commons Attribution License (for details please see creativecommons.org), which permits unrestricted use, distribution, and reproduction in any medium, provided the original author and source are credited. 
